\title{
The Effect of Perceived Managerial Support of Coaches' Organizational Commitment in Professional Football
}

\author{
Recep Gorgulu ${ }^{1}$, İhan Adilogullari ${ }^{2}$, Hakkı Ulucan ${ }^{3}$ \\ ${ }^{1}$ Elite Performance in Sport Research Group, Faculty of Sport Sciences, Bursa Uludag University, Turkey \\ ${ }^{2}$ Faculty of Sport Sciences, Canakkale Onsekiz Mart University, Turkey \\ ${ }^{3}$ Faculty of Sport Sciences, Erciyes University, Turkey \\ Correspondence: Recep Gorgulu, Elite Performance in Sport Research Group, Faculty of Sport Sciences, Bursa Uludag \\ University, Turkey
}

Received: December 27, 2018

Accepted: January 21, 2019

Online Published: January 28, 2019

doi:10.11114/jets.v7i3.3913

URL: https://doi.org/10.11114/jets.v7i3.3913

\begin{abstract}
The present study utilized the concept of commitment to explain the impact of managerial support on elite coaches' behaviour in professional football. Specifically, we aimed to examine the level of organizational commitment and managerial support according to the coaching level as well as the league categories of those elite football coaches. Furthermore, we hypothesized that managerial support would predict organizational commitment in elite football. Our sample comprised 300 football coaches drawn from the professional league categories. They completed the organizational commitment scale developed by Allen and Meyer $(1990 ; 1991)$ and the perceived managerial support questionnaire developed by Giray and Sahin (2012) followed by the inform consent in addition to the information sheet. Results of the present study revealed a significant difference between the level of elite coaches' organizational commitment and the perceived managerial support especially in terms of their coaching level and the league category. More interestingly, the results from the current study provide the evidence that managerial support predicts elite coaches' organizational support in professional football. The significance of this research rests in the insight provided into the managerial support that how coaches' organizational commitment effects and therefore their behaviour through the commitment to the club. We discuss the results in the context of specific dimensions in organizational behaviour in a coaching environment.
\end{abstract}

Keywords: organization, commitment, manager, coaching, education

\section{Introduction}

"Unless commitment is made, there are only promises and hopes ... no plans." Peter Drucker.

There has been growing recognition for the importance of understanding the experiences of organizational commitment in professional sports. Similar to other working areas of survival, stability and development are somehow depending on the quality of coaches' organizational commitment in sports. In the organizational behaviour literature, the commitment has been widely investigated due to it is predictive of work-related attitudes, beliefs and behaviours or its relationship with the organizational effectiveness (Bishop, Scott, Goldsby, \& Cropanzano, 2005; Williams \& Anderson, 1991). That's why organizational commitment is highly valuable and most studies highlighted that it has a great impact on the successful performance of an organization in the context of coaching (Eisenberger et al., 2001; Somers, 1995).

Meyer and Allen (1991) posit that when the effective, normative, or continuance commitment is high, the more positive behaviours will be occurring. The value of commitment to the organizational goals is recognized in the strategic approaches to human resources management that consider employee engagement as a means of enhancing performance (Green, Medlin, \& Whitten, 2004). In sport, from the perspective of engagement - similar to managers' but not at the same level - a coach has a formal authority and can utilize influence with or without an authority with the athletes (Dansereau, Graen, \& Haga, 1975) and also with the other members of the team. In other words, the relationship between a coach and a manager has similarities with the relationship between a supervisor and an employee similar to the any other organizational settings (e.g., business, education, military). Commitment to organizational behaviour literature has been widely studied due to it is predictive of work-related behaviours and attitudes in terms of motivation, 
engagement with others or its relationship with the organizational effectiveness (Bishop, Scott, Goldsby, \& Cropanzano, 2005; Williams \& Anderson, 1991). Research available to date that is grounded in sport-related studies have mainly concentrated on athletes (e.g., Gorgulu, 2019; Young \& Medic, 2011; Wilson et al., 2004) and only a few studies investigated coaches' commitment (Raedeke, 2004; Raedeke, Granzyk, \& Warren, 2000; Raedeke, Warren, \& Granzyk, 2002). However, these studies were mostly descriptive or measured certain predictor variables and inferred commitment dimensions based on clustering of predictors. For example, Raedeke (2004) conducted a one year follow up study to investigate swimming coaches' burnout and commitment profiles. In this investigation, results revealed that coaches who an obligatory commitment had reported lower intention to continue coaching than those who had functional commitment profile. In another study, researchers (Raedeke, Warren, \& Granzyk, 2002) investigated coaching commitment and turnover rates amongst USA swimming coaches' ages ranging from 17 to 81 years. Results of this study demonstrated that commitment was related to two dimensions such as satisfaction and investments and conjointly explained $65 \%$ of the variance in commitment. However, this all suggests that when it comes to predicting behavioural outcomes, assessment of the level of commitment alone may be less effective when predicting that what drives coaches to remain committed to their club. This provided an initial answer that a managerial support within the same club may provide insight into the level of coaches' commitment. From the perspective of the sporting development, behind the stars and most popular athletes that they are coaches and managers who devote many hours of their effort and time that usually requires too much commitment. Therefore, the managerial support may effect coaches' commitment in order to enhance athletic performance. Moreover, managerial support refers to the positive relationship between the manager and the coach and the main characteristics of the managerial support are trust, respect and willingness of the manager to help coaches (Gagnon \& Michael, 2004). In addition to this, managerial need support has been associated with higher levels of trust in the corporation, feelings of support and non-pressure at work and overall job satisfaction (Deci, Connell, \& Ryan, 1989), as well as higher levels of engagement (Deci et al., 2001) and performance (Baard, Deci, \& Ryan, 2004) among employees in the organizational environment.

To date, this research has largely focused on the relationship between professional football coaches' organizational commitment and their perceived managerial support. In addition, the perceived managerial support has a potential role and effects on the coaching performance and it can also be an important predictor for the efficacy of the coach, especially, under different circumstances that the coach may need the most (e.g, championship, finals, olympics). In other words, the higher is the level of support given to the coach by the manager; the coach will feel more secure against the negative effects of stressful conditions within the season or league. Furthermore, Michael and colleagues (Michael, Court, \& Petal, 2009) emphasised that the organizational commitment reflects the unique relationship between the individual (e.g., the coach) and the organization (e.g., the club) and this relationship is important to illustrate the individuals behaviour in the organization. For example, if the coach has a correct recognition of the club, he will accept the normalities and value-based system of the club. Therefore, the coach who perceives a high level of managerial support, when needed the coach is more likely to compensate the club support by the positive attitude and the desired working behaviours (Alijanpour, Dousti \& Khodayari, 2013). Meyer and Allen (1991) posit that when three dimensions of commitment are high (affective, normative and continuance commitment), behaviours will be more positive. Indeed coaches are the most responsible employees within the club/organization from athletic performance (Oliver, Hardy, \& Markland, 2010). Therefore, positive attitudes and behaviours would be more effective and predict to attain high levels of performance.

In this premise, we believe that one needs to shed light what is happening behind the stage as the coach who always has to be on a stage alone (e.g., in front of press conferences when losing or winning, newspapers, magazines). Furthermore, previous studies have been conducted with the convenience samples of non-elite or amateur coaches (e.g., Rezania \& Gurney, 2014). This approach should be viewed with the great caution and has been criticized for increasing the number of studies while making no or little contribution to the knowledge of the commitment studies in elite coaches. To our knowledge, there is no research on elite coaches (e.g., especially at professional level) that focused on specifically the effect of perceived managerial support on the coaches' organizational commitment in football. Thus, the purpose of this study was to explore elite coaches' perception and its effectiveness of the managerial support to their organizational commitment.

\section{Method}

\subsection{Participants}

We approached 500 coaches via online forms and the questionnaire pack by post and invited them to our study. However, we only received 365 responses from the coaches and 65 of the responses were excluded from the present study due to incomplete questionnaires or answering the same questions twice which was inaccurate response. Therefore, our final sample comprised 300 male professional coaches drawn from the professional league categories across Turkey (Super League $=\% 11.3, n=34 ; 1^{\text {st }}$ League $=\% 16.7, n=50 ; 2^{\text {nd }}$ League $=\% 30, n=90 ;$ and $3^{\text {rd }}$ League $=\% 42, n=126$ ). Participants represented a broad age range (Range $=30-50+$ years). Coaches who participated in our study reported their experiences in years $\left(M_{\text {experience }}=11.8, S D=5.8\right)$. 


\subsection{Instruments}

We used a personal information sheet to obtain a distribution of personal information (e.g., age, level of coaching, league category, and years of experience in coaching) of the participants.

\subsection{Organizational Commitment}

The Organizational Commitment (OC) scale developed by Allen \& Meyer $(1990 ; 1991)$ and adopted into the Turkish by Wasti (2000) was used to determine participants' level of commitment to their present organizations. The scale has three subscales reflecting a desire (affective commitment), a need (continuance commitment) and an obligation (normative commitment) in order to maintain employment within the organization. The participants rated each item on a 5-point Likert-type from 1 (strongly disagree) to 5 (strongly agree). The adopted version of the organizational commitment has 6 items for each subscale and 18 items in total. The Cronbach's alpha values for affective commitment, continuance commitment and the normative commitment were $0.82,0.87$, and 0.84 , respectively in the present study.

\subsection{Managerial Support}

The Perceived Managerial Support (PMS) questionnaire developed by Giray and Sahin (2012) was used to determine participants' perception of their belief on managerial support from their present football clubs. The questionnaire has three subscales reflecting workplace support, managerial support and co-workers support. However, we only used the managerial support subscale in the current study. The managerial support sub-scale has 11 items and each item was assessed on a 5-point Likert-type from 1 (totally disagree) to 5 (totally agree). The Cronbach alpha value was 0.90 for the managerial support scale in the present study.

\subsection{Data Analysis}

We employed a one-way analysis of variance (ANOVA) to obtain differences between the groups of perceived managerial support and the organizational commitment. Differences in league categories shown in table 1 and the level of coaching shown in Table 2 was further evaluated for significance with t-test post hoc comparisons. Cronbach's alpha analysis was employed to evaluate internal consistency for the perceived managerial support scale (0.90) and the organizational commitment questionnaire (0.84).

\section{Results}

Table 1. Comparison of the PMS and OC averages of the coaches participating in the study according to the league category variable

\begin{tabular}{lcccccc}
\hline & & N & Mean & SD & F & p \\
\hline \multirow{3}{*}{ PMS } & Super league & 34 & 4.22 & 0.15 & & $0.00 *$ \\
& 1. league & 50 & 3.72 & 0.43 & & \\
& 2. league & 90 & 3.41 & 0.64 & 31.609 & \\
\hline \multirow{4}{*}{ OC } & 3.league & 126 & 3.16 & 0.69 & & \multirow{2}{*}{$0.00 *$} \\
& Total & 300 & 3.45 & 0.69 & & \\
& Super league & 34 & 4.28 & 0.24 & & \\
& 1. league & 50 & 3.75 & 0.39 & & \\
\hline
\end{tabular}

Note: OC: Organizational Commitment, PMS: Perceived Managerial Support. ${ }^{*}=p>0.05$.

Table 1 showed that there was a significant difference between the groups according to coaches' league category on the organizational commitment and the perceived managerial support in the present study.

Table 2. Comparison of the PMS and OC averages of coaches participating in the study compared to the level of coaching

\begin{tabular}{lcccccc}
\hline & & Mean & SD & F & p \\
\hline \multirow{4}{*}{ PMS } & Pro Licence & 47 & 3.27 & 0.61 & & \\
& A Licence & 118 & 3.56 & 0.69 & 2.24 & 0.08 \\
& B Licence & 89 & 3.45 & 0.71 & & \\
\hline & Goal Keeper Coaches & 46 & 3.37 & 0.67 & & \\
OC & Total & 300 & 3.45 & 0.69 & & \\
& Pro Licence & 47 & 3.49 & 0.48 & & \\
& A Licence & 118 & 3.60 & 0.50 & 2.19 & 0.08 \\
& B Licence & 89 & 3.45 & 0.46 & & \\
& Goal Keeper Coaches & 46 & 3.41 & 0.61 & & \\
\hline
\end{tabular}

Note: OC: Organizational Commitment, PMS: Perceived Managerial Support. 
According to table 2, there was no significant difference between the groups according to the participants' level of coaching on the organizational commitment and perceived managerial support in the current study.

Table 3. The regression analysis shows the effect of coaches' perception of PMS on organizational commitment

\begin{tabular}{lcccccc}
\hline & $\boldsymbol{\beta}$ & $\mathbf{R}^{2}$ & $\mathbf{R}$ & $\mathbf{t}$ & $\mathbf{F}$ & $\mathbf{p}$ \\
\hline Regression coefficient & 2.20 & 0.31 & 0.56 & 18.83 & 136.45 & $\mathbf{0 . 0 0 0}^{\text {**** }}$ \\
PMS & 0.38 & & & 11.68 & & \\
\hline
\end{tabular}

Note: PMS: Perceived Managerial Support. $* * * p<0.001$.

In table 3 , the professional football coaches' perceived managerial support could statistically predict organizational commitment, $F(1,299)=136.45, p=0.000$ and the perceived managerial support accounted for $\% 31$ of the explained variability in organizational commitment. The regression equation was: predicted organizational commitment $=2.206+$ $0.388 \times$ (the level of perceived managerial support).

\section{Discussion}

The objective of the current study was to examine the relationship between elite coaches' organizational commitment and the level of perceived managerial support and therefore the effect of managerial support on the elite coaches' organizational commitment in the context of professional football. The results of the present study revealed that there is a significant difference according to coaches' league category (e.g., professional leagues) on their organizational commitment and the perceived managerial support (see. table 1). More specifically, the highest level of league category — namely super league coaches $(N=34)$ - reported highest scores on both the organizational commitment $(M=4.28 ; S D=0.24)$ and also the perceived managerial support $(M=4.22 ; S D=0.15)$ to compare with other league categories. However, this result can be speculative in a way that the statistical difference would be due to the league category as the highest scores reported by the Super League coaches had the smallest sample size in this study. Comparatively, the other league categories for example $1^{\text {st }}$, $2^{\text {nd }}$ and $3^{\text {rd }}$ leagues have very similar results in terms of organizational commitment and perceived managerial support. Interestingly, the lowest mean scores reported for the both organizational commitment and the perceived managerial support by the $3^{\text {rd }}$ league coaches who have the largest number of participants $(N=126)$ in this study. In order to provide meaningful contributions, comparative studies should recruit at least a similar number of participants for each coaching level in order to generalize the current results of the organizational and psychological elements based on the level of coaching. Despite the statistical differences on the organizational commitment and the perceived managerial support according to elite coaches' league category, we cannot simply and uniformly conclude for the elite coaches that working at the higher level of the league (e.g., Super league) associated with the higher level of perceived managerial support and therefore better organizational commitment. Contradictory to table 1, although results did not provide a significant difference (see table 2), there is a trend $(p=0.08)$ at the significance level of $p>0.05$. In this premise, the level of coaching has similar results in terms of the mean scores reported for the organizational commitment and the perceived managerial support. Results obtained from the current study revealed that the coaches who are working with a higher (Pro Licence) or a lower level (B Licence) of coaching licence are not associated with the level of the organizational commitment and the perceived managerial support in football context.

In the literature, research in organizational commitment was generally descriptive or comparative with some variables such as gender, age, and years of experience in coaching (Livingston \& Burley, 1996; Van Dick et al., 2004). However, to our knowledge, the present study provides the first findings that the elite coaches' perceived managerial support could predict the organizational commitment in professional football. Similar research design conducted to understand the relationship between the perceived organizational support and the organizational commitment of the general office staff for sport and the youth organization did not find any positive or meaningful results. In contrast, other researches (Rocha \& Chellad, 2011; Makanjee, Hartzer, \& Uys, 2006) found that increasing the perceived organizational support by the staff effects the positive beliefs towards the job and avoid withdrawing from the organization. Although the research population is different from the present study, our results are in line with the above studies. Furthermore, in the present study, we did not primarily aim to test organizational commitment dimensions (affective, normative or continuance commitment) separately but rather in general which was the main limitation of the current study. For example, Meyer and Allen (1991) stated that collectively when these dimensions are high; it will provide more positive organizational behaviour and therefore achieve the organizations' goals and its performance. In addition to this, Meyer and Allen $(1990 ; 1991)$ reported that effective commitment is directly related to on-the-job behaviours and performance. The literature in education and sport, scholars have investigated the relationship between commitment and athletic performance. For example, scholars (Turner \& Chelladurai, 2005) found that commitment can explain roughly 5\% of the variance in college coaches' athletic performance. Similar results were found $3 \%$ of the same variance can be explained through the commitment (Rocha \& Turner, 2008). Results from the both studies are in line with the results of the present study that is in coaches' favour for their commitment. 
It is not surprising given this example that at the end of the football season, underperforming teams always seek to change their prospects in their favour for the next season, especially, by making changes in their coaching staff (Fast \& Jensen, 2006). This increase the level of pressure on the coach as the coach feels the most responsible for their teams' success. Therefore, the managerial support in professional football should be viewed with the caution. The most parsimonious applied implication for the club managers in football would be that without having objective evidence (e.g., surveys, observational studies, and qualitative studies) other views will just become as speculative as either in a positive or negative way. More specifically, it can be conclude that the managerial support is an important and essential tool to enhance coaches' commitment, however, it is not very easy to measure or determine of this relationship (Dess \& Robinson, 1984). Therefore, educators, sport psychologists, managers, coaches and other managerial members of a team should take into account of the importance of the managerial support through the season especially when there is an ups and downs.

Obviously, there are areas that need to be addressed in future research. First future investigations on elite coaches should seek answers for the following questions that are worthy of research attention for example;

How to improve the perceived managerial support of coaches?

Are there any other factors moderating the effectiveness between the organizational commitment and the perceived managerial support?

From the point of applied implications, coaches in football should recognize that perceived managerial support can lead to effective commitment that helps to improve coaches' athletic performance. Thus, individualized treatments that come from direct supervisors and managers who play in the important role of the coaches' performance could be investigated in future to establish such interventions for the organizational behaviour discipline.

\section{Conclusion}

Similar to other organizations, the level of perceived managerial support that the coaches receive from their football clubs is an effective tool in order to improve the organizational commitment. The high level of perceived managerial support from a football club can create a positive behavioural environment between coaches and managers also with other members of the team that can provide the ground to emerge the dimensions of commitment. Thus, the managerial significance of this research rests in the insight provided into how the perceived managerial support can influence coaches' organizational commitment. The professional football clubs and federations can develop more effective education programmes in order to provide valuable managerial support to their coaches and also other members of the teams by institutionalizing their best practices.

\section{Compliance with ethical standards}

\section{Funding}

No funding was associated with this research.

\section{Conflict of interest}

The authors declare that they have no conflict of interest.

\section{Ethical approval}

All procedures performed in studies involving human participants were in accordance with the ethical standards of the institutional and/or national research committee and with the 1964 Helsinki declaration and its later amendments or comparable ethical standards.

\section{Informed consent}

Written informed consent was obtained from all individual participants included in the study.

\section{References}

Alijanpour, M., Dousti, M., \& Khodayari, A. (2013). The relationship between the preceived organizational support and organizational commitment in staff (A case study: General Office for sport and the youth, Mazandaran province). European Journal of Experimental Biology, 3(5), 165-171. https://doi.org/10.21511/imfi.13(3-1).2016.13

Allen, N. J., \& Meyer, J. P. (1990), The measurement and antecedents of affective, continuance and normative commitment to the organization, Journal of Occupational Psychology, 63, 1-18. https://doi.org/10.1111/j.2044-8325.1990.tb00506.x

Baard, P. P., Deci, E. L., \& Ryan, R. M. (2004). Intrinsic need satisfaction: A motivational basis of performance and well-being in two work settings. Journal of Applied Social Psychology, 34, 2045-2068. https://doi.org/10.1111/j.1559-1816.2004.tb02690.x

Bishop J.W., Scott, D. K., Goldsby M.G., \& Cropanzano R. A. (2005). Construct Validity Study of Commitment and 
Perceived Support Variables: a multifoci approach across different team environments. Group Organ Management, 30(2), 153-180. https://doi.org/10.1177/1059601103255772

Dansereau, F., Graen, G.B., \& Haga, W. (1975). A vertical dyad linkage approach to leadership in formal organizations. Organizational Behavior and Human Performance, 13, 46-78. https://doi.org/10.1016/0030-5073(75)90005-7

Deci, E. L., Connell, J. P., \& Ryan, R. M. (1989). Self-determination in a work organization. Journal of Applied Psychology, 74, 580-590. https://doi.org/10.1037/0021-9010.74.4.

Deci, E. L., Ryan, R. M., Gagne, M., Leone, D. R., Usunov, J., \& Kornazheva, B. P. (2001). Need satisfaction, motivation, and well-being in the work organizations of a former Eastern Bloc country: A cross-cultural study of self-determination. Personality and Social Psychology Bulletin, 27, 930-942.

https://doi.org/10.1177/0146167201278002

Dess, G. G., \& Robinson, R. B. (1984). Measuring organizational performance in the absence of objective measures: The case of the privately-held firm and conglomerate business unit. Strategic Management Journal, 5, 265-273. https://doi.org/10.1002/smj.4250050306

Eisenberger, S., Armeli, S., Rexwinkel, B., Lynch, P. D., \& Rhoades, L. (2001). Reciprocicaton of perceived organizational support. Journal of Applied Psychology, 86, 42-51. https://doi.org/10.1037/0021-9010.86.1.42

Fast, A., \& Jensen, D. (2006). The NFL coaching network: analysis of the social network among professional football coaches, Proceedings of the American Association for Artificial Intelligence Fall Symposium on Capturing and Using Patterns for Evidence Detection, available at: https://pdfs.semanticscholar.org/a1de/9c99b4ae3d67360bbe426a68935bc69c73fb.pdf accessed on the 03.10.2018.

Gagnon, M. A., \& Michael, J. H. (2004). Outcomes of perceived supervisor support for wood production employees. Forest Products Journal, 54, 172-177.

Giray, D. M., \& Sahin, N. D. (2012). Perceived Organizational, Supervisor and Co-worker Support Scales: A study for validity and reliability. Turkish Psychological Articles, 15, 10-11.

Gorgulu, R. (2019). Transformational Leadership Inspired Extra Effort: The Mediating Role of Individual Consideration of the Coach-Athlete Relationship in College Basketball Players. Universal Journal of Educational Research, 7(1), 157-163. https://doi.org/10.13189/ujer.2019.070120

Green, K. Medlin, B., \& Whitten, D. (2004). Developing optimism to improve performance: an approach for the manufacturing sector. Industrial Management \& Data Systems, 104, 106-114. https://doi.org/10.1108/02635570410522071

Livingston, M. M., \& Burley, K. (1996). The Importance of Being Femine: Gender Sex Role, Occupational and Marital Role Commitment, Journal of Social Behaviour And Personality, 11(5), 179-193.

Makanjee, R. C., Hartzer, Y., \& Uys, I. (2006). The effect of perceived organizational support on Organizational Commitment of Diagnostic Imaging Radiographers, Radiography, 12, 118-126.

https://doi.org/10.1016/j.radi.2005.04.005

Meyer, J., \& Allen, N. (1991). A three-component conceptualization of organizational commitment. Human Resource Management Review, 1, 61-89. https://doi.org/10.1016/1053-4822(91)90011-Z

Meyer, J., \& Allen, N. (1997). Commitment in the workplace: Theory, research, and application, Thousand Oaks, CA: SAGE Publications.

Meyer, J., Allen, N., \& Smith, C. (1993). Commitment to organizations and occupations: Extension and test of a three-component conceptualization. Journal of Applied Psychology, 78, 538-551. https://doi.org/10.1037/0021-9010.78.4.538

Michael, O., Court, D., \& Petal, P. (2009). International Journal of Educational Management, 2(3), 266-288. https://doi.org/10.1108/09513540910941766

Oliver, E. J, Hardy, J., \& Marldand, D. (2010). Identifying important practice behaviors for the development of high-level youth athletes: Exploring the perspectives of elite coaches. Psychology of Sport Exercise, 11, 433-443. https://doi.org/10.1016/j.psychsport.2010.05.004

Raedeke, T. D. (2004). Coach commitment and burnout: A one-year follow-up. Journal of Applied Sport Psychology, 16, 333-349. https://doi.org/10.1080/10413200490517995

Raedeke, T. D., Granzyk, T. L., \& Warren, A. (2000). Why coaches experience burnout: A commitment perspective. 
Journal of Sport \& Exercise Psychology, 22, 85-105. https://doi.org/10.1123/jsep.22.1.85

Raedeke, T. D., Warren, A. H., \& Granzyk, T. L. (2002). Coaching commitment and turnover: a comparison of current and former coaches. Research Quarterly for Exercise and Sport; 73(1), 73-86.

https://doi.org/10.1080/02701367.2002.10608994

Rezania, D., \& Gurney, R. (2014). Building successful student-athlete coach relationships: examining coaching practices and commitment to the coach, Springer Plus, 3(383), 1-11. https://doi.org/10.1186/2193-1801-3-383

Rocha, C. M., \& Turner, B. A. (2008). Organizational effectiveness of athletic departments and coaches, extra-role behaviors. Journal of Issues in Intercollegiate Athletics, 1, 124-144.

Rocha, M. C., \& Chellad, P. (2011). Relationship between organizational support and performance of college coaches: A mediational model. European Sport Management Quarterly, 3, 301-319. https://doi.org/10.1080/16184742.2011.577793

Somers, M. J. (1995). Organizational commitment, turnover and absenteeism: An examination of direct and interaction effects. Journal of Organizational Behavior, 16, 49-58. https://doi.org/10.1002/job.4030160107

Turner, B. A., \& Chelladurai, P. (2005). Organizational an occupational commitment, intention to leave, and perceived performance of intercollegiate coaches. Journal of Sport Management, 19, 193-211. https://doi.org/10.1123/jsm.19.2.193

Van Dick, R., Wagner, U., Stellmacher, J., \& Christ, O. (2004). The utility of a broader conceptualization organizational identification. Which aspect really matter?, Journal of Occupational and Organizational Psychology, 77, 171-191. https://doi.org/10.1348/096317904774202135

Wasti, S. A. (2000). Meyer ve Allen'in üç boyutlu örgütsel bağlıllk ölçeğinin geçerlilik ve güvenirlilik analizi. VIII Ulusal Yönetim ve Organizasyon Kongresi Bildirisi, Nevşehir (in Turkish).

Williams, L. J., \& Anderson, S. E. (1991). Job Satisfaction and Organizational Commitment as Predictors of Organizational Citizenship and In-Role Behaviors. Journal of Management, 17(3), 601-617. https://doi.org/10.1177/014920639101700305

Wilson, P.M., Rodgers, W.M., Carpenter, P.J., Hall, C., Hardy, J. \& Fraser, S.N. (2004). The relationship between commitment and exercise behavior. Psychology of Sport and Exercise, 5, 405-421. https://doi.org/10.1016/S1469-0292(03)00035-9

Young, B. W., \& Medic, N. (2011). Examining social influences on the sport commitment of masters swimmers. Psychology of Sport and Exercise, 12, 168-175. https://doi.org/10.1016/j.psychsport.2010.09.004

\section{Copyrights}

Copyright for this article is retained by the author(s), with first publication rights granted to the journal.

This is an open-access article distributed under the terms and conditions of the Creative Commons Attribution license which permits unrestricted use, distribution, and reproduction in any medium, provided the original work is properly cited. 